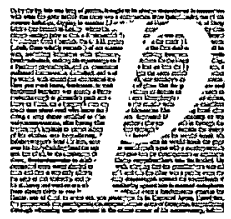

\title{
Ecfrasis y lecturas iconotextuales
}

\author{
Luz Aurora Pimentel
}

\section{Facultad de Filosofia y Letras}

\section{Universidad Nacional Autónoma de México}

\begin{abstract}
Piertos textos literarios, de naturaleza descriptivo-narrativa-que en una época incluso llegaron a constituir un género literario-establecen una relación tanto referencial como representacional con un objeto plástico que el propio texto propone como autónomo, como otro con respecto al discurso que intenta representarlo. Uno de los procedimientos retórico-discursivos utilizado en estas formas de representación es la llamada ecfrasis (ekphrasis). El sentido original de esta figura, tal y como lo entendian los rétores de los siglos III y IV d.C, y en especial Hermógenes, en su Ecphrasis. Progymnasmata, quedaba definido dentro de las formas de la descripción: se trataba de una descripción extendida, detallada, vívida, que permitía 'presentar el objeto ante los ojos;' una descripción que tenía la virtud de la energeia. ' Con el tiempo tales descripciones vívidas tendieron a organizarse en torno a objetos plásticos de tipo figurativo, a tal grado que el concepto acabó significando únicamente la representación verbal de un objeto plástico.

En nuestros días, dentro de la vasta literatura teórica sobre el tema, destacaré tres definịciones que me serán especialmente útiles para las breves reflexiones que habré de hacer en torno a esta relación intermedial, de carácter intersemiótico. Ya Leo Spitzer

Poligrafias IV (2003) 205-215

(C) Poligrafias. Revista de Literatura Comparada. División de Estudios de Posgrado, Facultad de Filosofia y Letras, Universidad Nacional Autónoma de México, Ciudad Universitaria, México 04510 DF. Tel. (525) 622 1835(6). Fax (525) 622 1801; 616 0047; 6221826.
\end{abstract}


la definía hace cuarenta años como "la descripción poética de una obra de arte pictórica o escultórica" (1962, 72); James Heffernan, de manera más abstracta, define la ecfrasis como "la representación verbal de una representación visual" $(1993,3)$, y Claus Clüver como "la representación verbal de un texto real o ficticio compuesto en un sistema sígnico no verbal" $(1994,26)$. Es interesante notar que las tres definiciones insisten en el carácter relacional del texto verbal con respecto al objeto plástico, lo cual permite extender el texto a una relación intersemiótica, $y$, puesto que el texto verbal asume la representación del objeto plástico, al que lee como si fuera un texto, la relación también se plantea como intertextual. Por otra parte, como ya lo apunta Spitzer, el texto ecfrástico surge de un impulso que se resuelve en la práctica textual que conocemos como descripción; un deseo de de-scribir (nótese el sentido etimológico de la palabra: describere-escribir a partir de), de re-presentar, de volver a presentar al otro no verbal. Destaca, asimismo, el carácter doblemente representacional de la ecfrasis, puesto que se trata de la representación verbal de una representación visual. Finalmente, en la definición de Clüver, el acento está puesto sobre la textualidad: el texto verbal representa al "texto" no verbal, compuesto en un sistema de signos no verbal.

No abordaré en este ensayo temas afines a la ecfrasis como el debate ya bicentenario, iniciado por Lessing, en torno a la propuesta horaciana sobre la relación de analogía entre la pintura y la poesía, el famoso dictum, ut pictura poesis, en términos de la supuesta y exclusiva espacialidad de las artes plásticas versus la igualmente supuesta y exclusiva temporalidad de las artes verbales. Mi propósito es explorar los límites de la textualidad en la ecfrasis, práctica discursiva que, al tiempo que declara al objeto plástico otro, extiende sus limites textuales para convertirlo en texto e incorporarlo como tal; abordaré, asimismo, las formas de relación entre el texto ecfrástico y el plástico, así como los grados de transformación/deformación que opera tal relación.

Para comenzar exploraremos brevemente los limites textuales y relacionales de este fenómeno verbal. Si la ecfrasis se define como la representación verbal de una representación visual, es claro que se trata de una operación esencialmente intertextual; no obstante, si, a su vez, la intertextualidad se define mínimamente como la presencia de un texto verbal en otro, en el caso que nos ocupa, la presencia de una representación visual en un texto verbal establece una relación que Peter Wagner $(1996,17)$ ha llamado intermedialidad, misma que define como "una subdivisión de la intertextualidad." La relación intermedial pone en juego por lo menos dos medios de significación y de representación. No obstante, si bien la relación intermedial, como la intertextual, también puede darse en las modalidades de la cita puntual y la alusión, el efecto sobre el texto no es de la misma naturaleza. En la cita puntual, el texto verbal citado sufre una serie de transformaciones debido al nuevo contexto circundante, pero las palabras como tales son las mismas. En el caso del objeto plástico citado la transformación es de otro orden; en su relación con el texto verbal la imagen evocada puede desembocar en un verdadero iconotexto (Wagner, 1996): no sólo la representación visual es leida/escrita-de hecho descrita-como texto sino que al entrar en 
relaciones significantes con el verbal le añade a este último formas de significación sintética que son del orden de lo icónico y de lo plástico, construyendo un texto complejo en el que no se puede separar lo verbal de lo visual: un iconotexto. Esto ocurre aun en la forma más simple y abreviada de la ecfrasis, la citación, en la que ni siquiera se puede hablar de un trabajo descriptivo de transposición, selección, reorganización y transformación del objeto plástico en un objeto verbal. En su forma de alusión o de cita-con frecuencia un símil o una analogía que puede incluir el nombre del cuadro-, la ecfrasis como ejercicio descriptivo es sólo en potencia, pero es un potencial que se realiza plenamente en las ecfrasis más extendidas que construyen una suerte de objeto plástico verbal (valga la paradoja) que entra en complejas relaciones de identidad y otredad con el objeto plástico del que se quiere representación y con el texto/contexto en el que la ecfrasis ha sido inscrita. Claro está que, en rigor, el concepto de iconotexto designa una producción intermedial de texto e imagen en yuxtaposición, como en las Biblias ilustradas, los libros de horas, los emblemas, las novelas ilustradas, los comics, o los collages surrealistas, entre otros. En esa clase de textos híbridos, tanto la imagen como la palabra tienen una presencia efectiva, material, en el texto que tejen conjuntamente. No obstante, ciertos textos-como el poema de Octavio Paz, "Cuatro chopos," que analizaremos más tarde - se construyen como una verdadera invitación a una lectura iconotextual, de tal suerte que aun cuando la imagen plástica no esté materialmente presente en el texto, la lectura más productiva se da en la interacción creadora, incluso lúdica, entre texto verbal y objeto plástico.

Ahora bien, en tanto que representación, el objeto plástico descrito verbalmente puede ser, como bien lo advierte Clüver, real o ficticio; de hecho el paradigma mismo de la ecfrasis, el escudo de Aquiles en la Ilíada, no existe fuera de la descripción que lo construye. De tal suerte que podemos hablar de ecfrasis referencial, cuando el objeto plástico tiene una existencia material autónoma, o de ecfrasis nocional cuando el objeto "representado" solamente existe en y por el lenguaje, como en el caso del escudo de Aquiles. Hay, sin embargo, un tipo de ecfrasis intermedio que yo querría llamar ecfrasis referencial genérica, y que con frecuencia se observa en textos ecfrásticos que, sin designar un objeto plástico preciso, proponen configuraciones descriptivas que remiten al estilo o a una sintesis imaginaria de varios objetos plásticos de un artista. Ejemplo de la ecfrasis referencial genérica serían los "cuadros" descriptivos en Proust que evocan a Monet, sin remitir a uno solo, o bien al surtidor de Hubert Robert que tiene como referente el "tipo" de fuentes y surtidores diseñados y pintados por Robert, pero no un objeto único. ${ }^{2}$

No obstante, real, nocional o genérico, la descripción de un objeto plástico en general tiende a anunciarse como tal y pretende ser su equivalente verbal. En esta fase de la construcción verbal, la ecfrasis parte de su origen descriptivo para establecer una relación analógico referencial con el objeto a representar. En ocasiones el objeto incluso es citado con todas sus particularidades, con nombre, apellido y hasta domicilio-por así decirlo-como ocurre con el alter ego ecfrástico de Odette de Crécy en Un amor de Swann, de Proust. A los ojos de Swann, su amada se parece a una 
obra de Boticelli, Zéfora, la hija de Jetro, en un fresco sobre la vida de Moisés pintado en la capilla Sixtina. Tanto la referencia como la descripción constituyen una suerte de invitación al lector para que lleve a cabo un "cotejo." Mas el "cotejo" no procede meramente como registro de semejanzas, o de exhaustividad en la descripción, porque habría que considerar un fenómeno de capital importancia para esta práctica discursiva: que toda mirada transforma al objeto plástico en un texto para leer, y, por lo tanto, el objeto plástico se convierte en tantos textos como miradas se fijen en él. Y es que, en el acto mismo de describir, el poeta o novelista selecciona, reorganiza, jerarquiza; resignifica, en una palabra, al objeto representado, convirtiéndolo en un texto significante, en ese otro del texto verbal. Más aún, en el acto de lectura, el lector también resignifica ambos textos, el plástico y el ecfrástico sobre los mismos principios de selección, jerarquización y organización de los detalles que el texto le ofrece. Ahora bien, el texto verbal confiere significaciones al texto plástico que no necesariamente le son propias, significaciones que forman parte del contexto verbal en el que se inscribe el texto ecfrástico, de modo que, paradójicamente, si el impulso ecfrástico tiende, en un primer momento, a una relación analógica con el objeto plástico, a la larga termina "pareciéndose" más a la red de significaciones del contexto verbal que al objeto que pretende representar. Por otra parte, la ecfrasis misma, en tanto que lectura/escritura del texto visual modifica nuestra percepción del objeto plástico, reorganiza nuestra mirada y la jerarquiza de acuerdo con los valores establecidos por el texto verbal.

De modo correlativo, la percepción del objeto plástico afecta nuestra lectura del texto ecfrástico de varias maneras. En primer lugar, permite lo que llamaríamos un incremento icónico en la significación verbal: al evocar un cuadro para caracterizar a un personaje - Odette de Crécy como figura de Botticelli, por ejemplo-la imagen que se le aplica al personaje no es de naturaleza verbal sino pictórica, una imagen plástica evocada por el nombre y descrita en sus particularidades seleccionadas; la significación visual opera así como una suerte de retrato que complementa, culmina o intensifica al "retrato hablado."

En segundo lugar el texto ecfrástico tiende, o bien a una suerte de fijación de la imagen, debido a que se trata de la representación verbal de una representación visual; o bien a un impulso narrativo que dinamiza al objeto de la representación. No olvidemos que en la época helenistica la ecfrasis fue definida como una descripción tan vívida y detallada que tenía la virtud de la energeia (cf. Krieger). Y es esta fuerza, esta energía, la que imprime el carácter dinámico, con frecuencia narrativo, de la ecfrasis. Podríamos decir incluso que ese impulso narrativo que dinamiza al texto visual ya está potencialmente en la sola "secuencia" descriptiva. Como lo plantea Heffernan, de manera humorística, "la ecfrasis es dinámica y obstétrica porque ayuda al arte visual, preñado de narratividad, a parir ese impulso embrionariamente narrativo, haciendo explícita la historia implícita en el arte visual" $(1993,5) .{ }^{3}$ Claro está que Heffernan piensa solamente en aquellos cuadros que se inspiran en algún relato (los cuadros con tema bíblico, mítico o histórico); sin embargo, aquí, de hecho, se trata de una suerte de "ecfrasis inversa," por así decirlo: la representación visual de un momento narrativo. 
En tales cuadros el origen es ya explícitamente y desde siempre, narrativo. Pero el impulso narrativo de la ecfrasis va mucho más allá, pues es el propio texto ecfrástico el que, al dinamizar la descripción, literalmente construye un relato donde no necesariamente lo hay. En otras palabras, la pintura figurativa, por el solo hecho de representar acción humana, tiene un potencial narrativo que el texto ecfrástico tiende a realizar, (ins)(des)cribiendo el gesto en un flujo temporal narrativamente articulado, un antes, un después; una causa, un efecto.

En tercer lugar, el texto visual, por su propia materialidad, así como por todas las otras significaciones potenciales, opone resistencia a la resignificación que el texto ecfrástico opera, produciéndose así interesantes efectos de sentido irónico (como la virginidad botticelliana de Odette-Zéfora, o la inmortalidad del Ozymandias de Shelley) o simbólico (como la urna de Keats, o los chinos del poema de Yeats, "Lapislázuli," o los cuatro árboles de Monet en Octavio Paz).

Finalmente, por el pacto referencial implícito en el mismo principio ecfrástico, aun la ecfrasis nocional produce la ilusión de un objeto plástico autónomo y silencioso que pide y se presta a ser $d e$-scrito, re-presentado. Así, la ecfrasis nocional es la paradoja del objeto que se representa en el acto de ser presentado, que se resignifica significándose. El escudo de Aquiles, en la Ilíada, o "El puerto de Carquethuit" del pintor Elstir, en $A$ la sombra de las muchachas en flor, de Proust, sólo existen en y por el lenguaje, pero su creación discursiva conlleva la ilusión de ser un objeto plástico autónomo, de ese otro silencioso, de un mundo sensible que busca ser inteligible. Mas todo, silencio y discurso, el mundo de lo sensible y el de lo inteligible, todo no es sino una ilusión producida por el propio discurso, extendiendo los limites de la textualidad hacia la intertextualidad y la intermedialidad, y, finalmente, hacia la estasis y el silencio.

Con objeto de concretar en el análisis algunas de las propiedades de la ecfrasis, he elegido un poema de Octavio Paz que establece un contrato descriptivo explícito con un cuadro de Claude Monet. Se trata de "Cuatro chopos," uno de los poemas de Visto y dicho, dentro del libro Árbol adentro (1976-1988). Unifica a la mayoría de los poemas de Visto y dicho un impulso descriptivo que se resuelve con frecuencia en una meditación poética sobre objetos plásticos-Miró, Duchamp, Monet, entre otros-0 en la descripción de paisajes- - "Central Park." Desde el título y la dedicatoria a Claude Monet, hay una clara orientación paratextual que nos invita a leer el poema, entre muchas otras formas, como la descripción de un cuadro específico. Entre 1891 y 1892, Monet pintó su famosa serie de chopos desde su barca-taller en la región de Limetz, los remansos pantanosos del rio Epte. Casi todos los cuadros incluyen el nombre "chopo" (peuplier) en el título-Peupliers au bord de l'Epte, effet du soir, Rangée de peupliers, Trois peupliers. Curiosamente uno de los más famosos, el de los cuatro chopos al que claramente se refiere el poema de Paz, es justamente el que no incluye la palabra peupliers y se llama solamente "Les quatre arbres" (ver figura 1). No obstante, y desde el punto de vista figurativo, se trata de los mismos chopos que ha estado pintando Monet de manera obsesiva en distintos momentos del día, del año, con distintas 


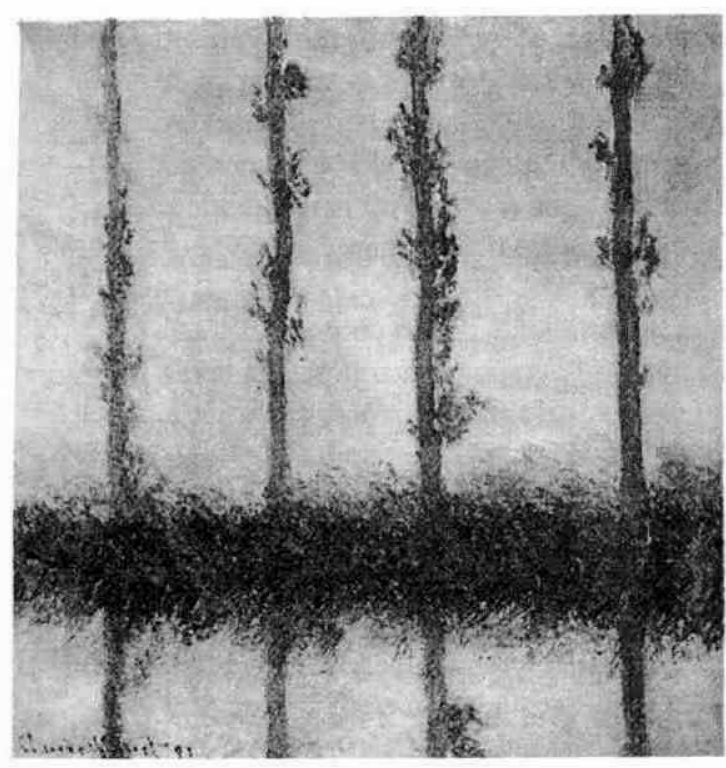

Figura 1 gradaciones de luminosidad. Son, pues, chopos, aunque no se llamen así en este cuadro: son y no son. Hay en el poema, quizá, un interesante juego de identidades al invocar y abolir al mismo tiempo el cuadro de Monet, al hacer de los cuatro chopos verbales "un solo chopo" y "ninguno."

\section{Cuatro chopos}

\section{A Claude Monet}

Como tras de si misma va esta línea

por los horizontales confines persiguiéndose

y en el poniente siempre fugitivo en que se busca se disipa

-como esta misma línea por la mirada levantada vuelve todas sus letras una columna diáfana resuelta en una no tocada ni oida ni gustada mas pensada flor de vocales y de consonantes

- como esta linea que no acaba de escribirse $y$ antes de consumarse se incorpora sin cesar de fluir pero hacia arriba:

los cuatro chopos.

\section{Aspirados}

por la altura vacía y allá abajo, en un charco hecho cielo, duplicados, los cuatro son un solo chopo y son ninguno.

Atrás, frondas en Ilamas que se apagan -la tarde a la derivaotros chopos ya andrajos espectrales interminablemente ondulan interminablemente inmóviles.

El amarillo se desliza al rosa, se insinúa la noche en el violeta.

Entre el cielo y el agua hay una franja azul y verde: 
sol y plantas acuáticas, caligrafia llameante escrita por el viento.

Es un reflejo suspendido en otro.

Tránsitos: parpadeos del instante.

El mundo pierde cuerpo, es una aparición, es cuatro chopos, cuatro moradas melodías.

Frágiles ramas trepan por los troncos.

Son un poco de luz y otro poco de viento.

Vaivén inmóvil. Con los ojos

las oigo murmurar palabras de aire.

El silencio se va con el arroyo, regresa con el cielo.

Es real lo que veo: cuatro chopos sin peso plantados sobre un vértigo. Una fijeza que se precipita hacia abajo, hacia arriba, hacia el agua del cielo del remanso en un esbelto afán sin desenlace mientras el mundo zarpa hacia lo obscuro.

Latir de claridades últimas:

quince minutos sitiados que ve Claudio Monet desde una barca.

En el agua se abisma el cielo, en sí misma se anega el agua, el chopo es un disparo cárdeno: este mundo no es sólido.

Entre ser y no ser la yerba titubea, los elementos se aligeran, los contornos se esfuman, visos, reflejos, reverberaciones, centellear de formas y presencias, niebla de imágenes, eclipses, esto que veo somos: espejeos.

El poema, dividido en 14 estrofas irregulares, comienza en un movimiento horizontal, una línea que va "tras de sí misma," hasta la disipación, en un esfuerzo de tocar al otro que es el cuadro. En la segunda estrofa, la línea se repliega sobre sí misma y obliga al lector a levantar la mirada hasta la primera línea, en un movimiento que ahora es claramente vertical y especular. La línea que dirige a la mirada, in-formándola, se convierte en "columna diáfana" en la que se funden sinestésicamente los sentidos y los mundos vegetal y verbal: "flor de vocales y de consonantes," que ya anuncia su 
musicalidad, si bien por preterición: "una no tocada ni oida ni gustada mas pensada / flor de vocales y consonantes." El primer verso de la tercera estrofa interrumpe esta interpenetración del mundo y la escritura para afirmar su paradójica incompletud aunada a su deseo de elevación; más aún, la línea no acaba de escribirse y sin embargo consuma la transformación de las estrofas en árboles. El verso aislado- "los cuatro chopos"- es el gozne de articulación entre la tercera y la cuarta estrofa, pero también el remate de la columna transfigurada en árbol. Es entonces que estalla en polisémica significación la palabra "linea." Por una parte significa el verso, pero también la linea que conecta el poema con el cuadro, ya que es evidente - y quizá es el poema de Paz el que lo hace más evidente al darle un lugar jerárquico tan alto que el principio compositivo dominante del cuadro de Monet es justamente la linea: la línea como trazo dominante: cada chopo es, ante todo, una línea. El poema, por su parte, hace de cada estrofa un árbol que comienza en una línea. Asi, las primeras tres estrofas están animadas por lo que yo llamaría (modificando un hallazgo descriptivo de Spitzer) una "onomatopeya sintáctica," ya que las palabras parecen hacer lo que dicen: 1) las lineas se persiguen y reflejan en su mismidad/otredad; 2) la línea de la segunda estrofa, al decirlo, obliga, efectivamente, a levantar la mirada hacia la primera; 3) las tres primeras estrofas materialmente se convierten en "columna diáfana" que fluye "hacia arriba;" 4) en la tercera estrofa, la incompletud de la linea se refleja en la estrofa trunca que se completa en la cuarta que es su reflejo- "Aspirados / por la altura vacia..."(ver figura 2)

La cuarta estrofa mira en dos direcciones, hacia arriba y hacia abajo, en un sistema de reflejos sonoros que se expresa en aliteraciones - "charco hecho cielo"-que al mismo tiempo son paradojas que concilian las direcciones opuestas - charco/cielo-y que preparan para la serie de antitesis que aquí se inicia: "interminablemente inmóviles," "vaivén inmóvil," "el agua del cielo." De este modo, si las cuatro estrofas iniciales del poema por presión ecfrástica se convierten en árboles-lineas, los cuatro

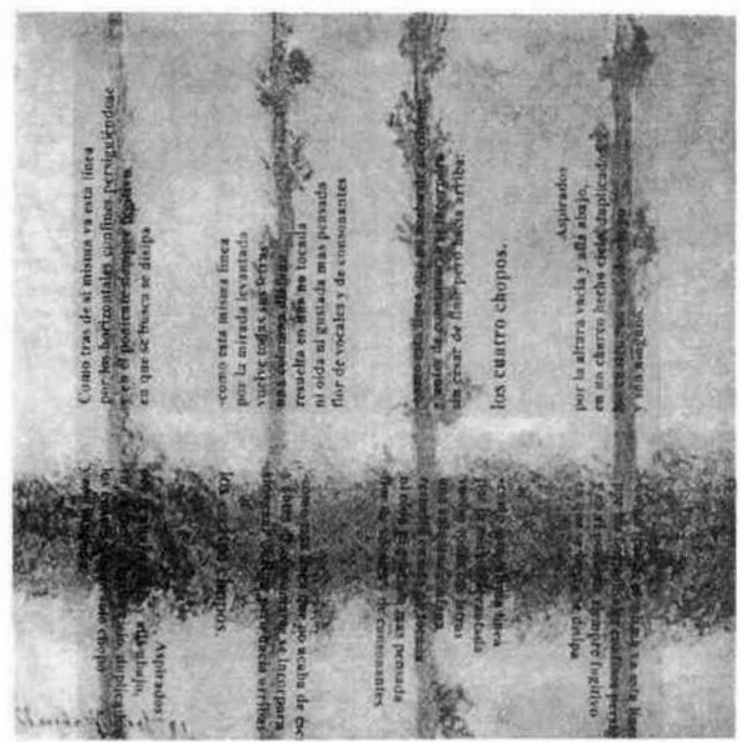

Figura 2 árboles de Monet bien podrían transformarse en un texto, en el cuaderno rayado del mundo sobre el cual el viento escribe su "caligrafia llameante." Porque si el cuadro in-forma las estrofas; la poesía invita a otra lectura del cuadro en un incesante juego iconotextual. Al leer los árboles como líneas horizontales, no sólo se evoca la escritura - esa caligrafia llameante del color y de la forma - sino también la música, en una suerte de pentagrama-tetragrama, mejor dicho sobre el que se pautan aquellas "cuatro moradas melodias" (ver figura 3).

A partir de esta escritura del mundo, plantada "sobre un vértigo," el poema se 
musicalidad, si bien por preterición: "una no tocada ni oída ni gustada mas pensada ، flor de vocales y consonantes." El primer verso de la tercera estrofa interrumpe esta interpenetración del mundo y la escritura para afirmar su paradójica incompletud aunada a su deseo de elevación; más aún, la línea no acaba de escribirse y sin embargo consuma la transformación de las estrofas en árboles. El verso aislado- "los cuatro chopos"--es el gozne de articulación entre la tercera y la cuarta estrofa, pero también el remate de la columna transfigurada en árbol. Es entonces que estalla en polisémica significación la palabra "línea." Por una parte significa el verso, pero también la línea que conecta el poema con el cuadro, ya que es evidente-y quizá es el poema de Paz el que lo hace más evidente al darle un lugar jerárquico tan alto-que el principio compositivo dominante del cuadro de Monet es justamente la línea: la línea como trazo dominante: cada chopo es, ante todo, una línea. El poema, por su parte, hace de cada estrofa un árbol que comienza en una línea. Asi, las primeras tres estrofas están animadas por lo que yo llamaría (modificando un hallazgo descriptivo de Spitzer) una "onomatopeya sintáctica," ya que las palabras parecen hacer lo que dicen: 1) las líneas se persiguen y reflejan en su mismidad/otredad; 2) la línea de la segunda estrofa, al decirlo, obliga, efectivamente, a levantar la mirada hacia la primera; 3 ) las tres primeras estrofas materialmente se convierten en "columna diáfana" que fluye "hacia arriba;" 4) en la tercera estrofa, la incompletud de la línea se refleja en la estrofa trunca que se completa en la cuarta que es su reflejo-_Aspirados / por la altura vacía..."(ver figura 2)

La cuarta estrofa mira en dos direcciones, hacia arriba y hacia abajo, en un sistema de reflejos sonoros que se expresa en aliteraciones-"charco hecho cielo"-que al mismo tiempo son paradojas que concilian las direcciones opuestas - charco/cielo-y que preparan para la serie de antítesis que aquí se inicia: "interminablemente inmóviles," "vaivén inmóvil," "el agua del cielo." De este modo, si las cuatro estrofas iniciales del poema por presión ecfrástica se convierten en árboles-líneas, los cuatro

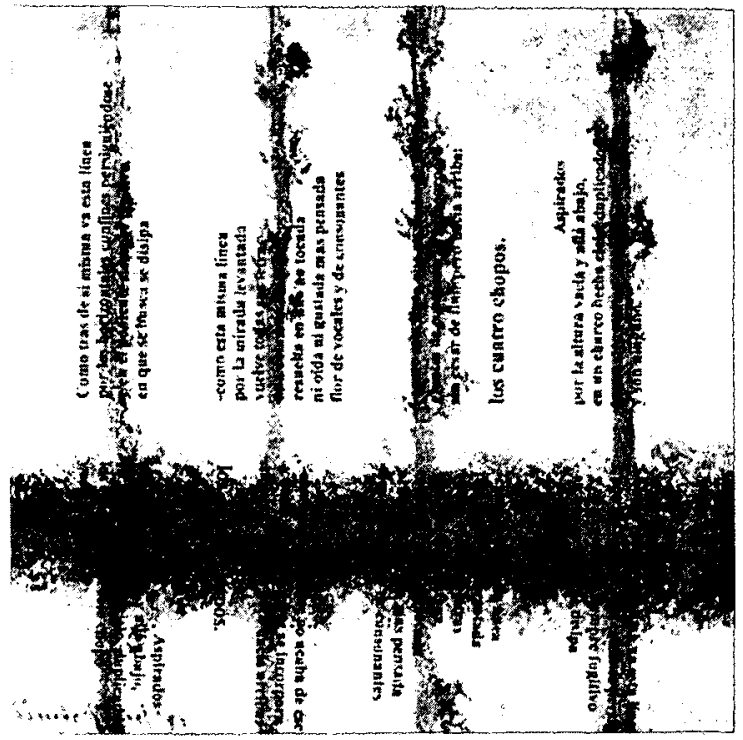

Figura 2 árboles de Monet bien podrían transformarse en un texto, en el cuaderno rayado del mundo sobre el cual el viento escribe su "caligrafia llameante." Porque si el cuadro in-forma las estrofas; la poesía invita a otra lectura del cuadro en un incesante juego iconotextual. Al leer los árboles como líneas horizontales, no sólo se evoca la escritura-esa caligrafia llameante del color y de la forma-sino también la música, en una suerte de pentagrama-tetragrama, mejor dicho-sobre el que se pautan aquellas "cuatro moradas melodías" (ver figura 3).

A partir de esta escritura del mundo, plantada "sobre un vértigo," el poema se 
mueve hacia la irrealidad, hacia la profunda ambigüedad de los reflejos; todo es reflejo y está a la deriva, una materialidad que se disipa en el ocaso, en la irrealidad, como si el poeta indagara en la naturaleza misma de la realidad, porque si el reflejo tiene la misma solidez que la realidad, si "el mundo pierde cuerpo," luego entonces ¿la realidad misma sería un reflejo?, ¿"un reflejo suspendido en otro?"

Asi, "plantados sobre un vértigo," todas las antitesis y paradojas literalmente nos desquician, nos hacen perder incluso el sentido de la ubicación: si arriba es abajo y viceversa, si el agua está en el cielo y el cielo se abisma en el agua, nada es y todo es. Dos hermosas figuras resumen la incertidumbre de la realidad y su especularidad. La primera es un extraño

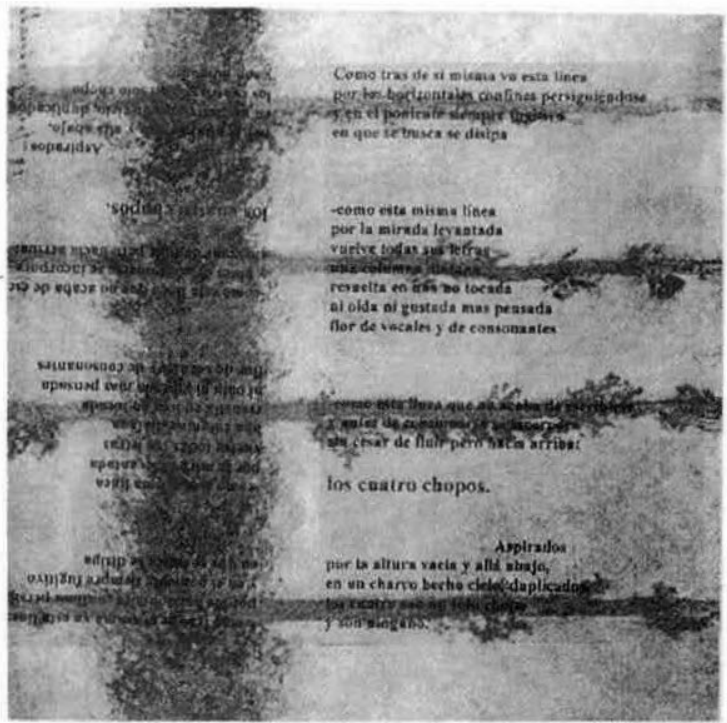

Figura 3 quiasmo que en su forma de espejo encierra la paradoja: "En el agua se abisma el cielo, / en si misma se anega el agua." En un primer momento parecería no corresponder a la figura - cuya estructura, como bien sabemos, es ABBA - ya que, si "agua" es A y ocupa la posición inicial y final en el enunciado, y si B es "cielo," "en sí misma" romperia el quiasmo pues repetiría $\mathbf{A}$. Sin embargo, considerando que el cielo se hace "charco" ("un charco hecho cielo"), el agua cobra, paradójicamente, un valor de "cielo"en esta posición intermedia. Finalmente, la forma misma del quiasmo resuena visualmente en el cuadro, sólo que de manera vertical, donde los árboles ocuparían la posición A y la franja de tierra en la que están plantados, la posición B. Si el cuadro de Monet puede ser leído como un quiasmo visual y vertical, esta posibilidad de lectura ha sido activada desde la poesía.

La última figura que evoca al cuadro en su estructura especular es el verso que cierra el poema: "esto que veo somos: espejeos." El verso, dividido en dos partes por una cesura fuerte, es una estructura especular en la que los elementos de la primera mitad -veo," "esto," el quiásmico "somos"-no sólo están reflejados sino contenidos y unificados en una sola palabra: "espejeos," cuyo centro, la "p" es exactamente el reflejo es decir la imagen invertida de la "q" del "que" de la primera parte del verso. Si verticalizamos la división volvemos a los cuatro chopos de Monet. 


\section{esto que veo somos:}

\section{esqpejeos}

\section{es/es \\ qp \\ eo/eos \\ so/os/eos}

Esta lectura iconotextual del cuadro y del poema en fructifera interacción es, pienso, la puesta en escena de una invitación explícita. El poema se nos propone como una representación verbal de un cuadro de Monet y se inscribe así en la serie de poemas en torno a las artes plásticas que Paz reunió en el volumen Visto y dicho. Aun cuando la intención ecfrástica es clara, y todo el poema moviliza estrategias descriptivas que remiten al cuadro, el solo hecho de que se trate de un texto verbal-como lo hemos hecho notar en la parte teórica de este trabajo-hace que los elementos descritos queden inscritos en una serie de significaciones que si bien en un momento dado también pueden coincidir con la poética impresionista del pintor, son esencialmente preocupaciones recurrentes del poeta; en otras palabras, el texto ecfrástico no re-presenta sino que re-significa al objeto plástico al entrar en una red textual y contextual diferente, tramada por la visión del poeta. Es por ello que, además de la lectura iconotextual, casi pactada por el poeta, una lectura intertextual pondría en órbita otros poemas de Paz-pienso de manera especial en los de Ladera Este-que también constituyen una meditación sobre la irrealidad del mundo, el Maya de los textos Védicos que en cierta medida inspiran estas reflexiones. De cualquier modo, por la vía iconotextual o intertextual, el cuadro de Monet es para el poeta no sólo un referente, un punto de partida material para la recreación del mundo, sino también un vehículo para pensar la irrealidad de la realidad, sus espejismos: "esto que veo somos: espejeos." 


\section{Notas}

' Citado en Murray Krieger $(1992,7)$.

${ }^{2}$ Para un análisis detallado de este objeto ficcional--el surtidor de Hubert Robert-ver el capítulo 6 de mi libro El espacio en la ficción. Ficciones espaciales (2001).

3 "ekphrasis is dynamic and obstetric; it typically delivers from the pregnant moment of visual art its embrionically narrative impulse, and thus makes explicit the story that visual art tells only by implication"

\section{Obras citadas}

Heffernan, James A. W. 1993. Museum of Words. The Poetics of Ekphrasis from Homer to Ashbery. Chicago and London: The University of Chicago Press.

Peter Wagner (ed.). 1996. Icons - Texts - Iconotexts. Essays on Ekphrasis and Intermediality. Berlin, New York: Walter de Gruyter.

Krieger, Murray. 1992. Ekphrasis. The Illusion of the Natural Sign. Baltimore and London: The Johns Hopkins University Press.

Spitzer, Leo. 1962. "The 'Ode on a Grecian Urn,' or Content vs Metagrammar," en Essays on English and American Literature. Anna Hatcher (ed.). Princeton: Princeton University Press.

Lagerroth, Ulla-Britta, Hans Lund, Erik Hedling (eds.). 1997. Interart Poetics. Essays on the Interrelations of the Arts and Media.

Clüver, Claus. 1997. "Ekphrasis Reconsidered. On Verbal Representations of Non-Verbal Texts" (en Lagerroth, 1997, 19-33)

Wildenstein, Daniel. 1996. Monet. Catalogue raisonné. Werkverzeichnis, III. Köhln : Taschen.

\section{Ilustraciones}

Figuras 1, 2 y 3, Monet, Les quatre arbres (1891), 82 x $81.5 \mathrm{~cm}$. The Metropolitan Museum of Art, New York. En Wildenstein (1996, III, 522) 